\title{
Pengaruh Penggunaan Metode Diskusi Dan Demonstrasi Serta Gaya Belajar Terhadap Hasil Belajar Biologi Siswa Kelas VIII SMP Negeri 2 Larantuka Kabupaten Flores Timur
}

\author{
Maria Letisia Lipat Tupen \\ Dosen STKIP Hermon Timika, Papua \\ Email: marialetisia92@gmail.com
}

\begin{abstract}
Abstrak. Tujuan penelitian ini adalah untuk mengetahui (1) Pengaruh penggunaan metode diskusi dan demonstrasi terhadap hasil belajar Biologi ranah kognitif pada siswa kelas VIII SMP Negeri 2 Larantuka Kabupaten Flores timur; (2) Pengaruh gaya belajar yang berbeda terhadap hasil belajar Biologi ranah kognitif pada siswa kelas VIII SMP Negeri 2 Larantuka Kabupaten Flores timur; (3) Pengaruh interaksi antara metode dengan gaya belajar yang berbeda terhadap hasil belajar Biologi ranah kognitif pada siswa kelas VIII SMP Negeri 2 Larantuka Kabupaten Flores Timur. Rancangan yang digunakan dalam penelitian ini adalah Quasy Experiment: Non Equivalent Control Group Pretest Posttest Design. Populasi penelitian ini adalah seluruh siswa kelas VIII SMP Negeri 2 Larantuka yang berjumlah 193 orang pada semester genap tahun pelajaran 2015/2016. Sampel pada penelitian ini adalah siswa kelas VIII A sebagai kelas yang diajar dengan menggunakan metode diskusi dengan jumlah 31 siswa dan Kelas VIII D sebagai kelas yang diajar dengan menggunakan metode demonstrasi dengan jumlah 31 siswa. Teknik pengambilan sampel dengan “Cluster Pusposive Sampling”. Teknik pengumpulan data hasil belajar Biologi menggunakan tes dan untuk data gaya belajar siswa menggunakan angket gaya belajar. Teknik analisis data dengan menggunakan Analisis varians (ANAVA) dua jalan. Hasil penelitian ini disimpulkan sebagai berikut; (1) Ada pengaruh penggunan metode diskusi terhadap hasil belajar Biologi siswa SMP Negeri 2 Larantuka Kabupaten Flores Timur; (2) Tidak ada pengaruh gaya belajar yang berbeda terhadap hasil belajar Biologi siswa SMP Negeri 2 Larantuka Kabupaten Flores Timur; (3) Tidak ada pengaruh interaksi antara penggunaan metode dengan gaya belajar yang berbeda terhadap hasil belajar Biologi siswa SMP Negeri 2 Larantuka Kabupaten Flores Timur.
\end{abstract}

Kata Kunci: Metode Diskusi, Metode Demonstrasi, Gaya Belajar, Hasil Belajar Biologi

\section{PENDAHULUAN}

Proses pembelajaran yang berkualitas ditandai dengan adanya interaksi yang baik antara guru dan siswa. Dalam rangka perancangan dan pelaksanaan pembelajaran yang sistematik, pemilihan strategi pembelajaran perlu mendapatkan perhatian secara saksama untuk menciptakan pengelolaan proses belajar mengajar yang efektif. Ambarina dalam Muldayanti, (2013:12) menyatakan bahwa proses pembelajaran pada dasarnya merupakan interaksi guru dengan siswa untuk mencapai tujuan belajar yang diharapkan.

Guru merupakan ujung tombak dalam pembelajaran, untuk itu guru dituntut harus memiliki kemampuan yang baik dalam mengajar. Seorang guru yang professional harus memiliki kemampuan untuk mengaplikasikan berbagai metode dan strategi pembelajaran. Hal ini menjadi penting untuk diperhatikan karena salah satu penentu berhasil atau tidaknya suatu proses pembelajaran adalah ketepatan guru dalam memilih dan menerapkan metode pembelajaran. Hamdani (2011:80) menyatakan bahwa metode pembelajaran adalah cara yang digunakan guru untuk menyampaikan pelajaran kepada siswa. Oleh karena itu, peranan metode mengajar sebagai alat untuk menciptakan proses pembelajaran sangat penting. Dalam hal ini guru harus 
mampu memilih strategi dan metode pembelajaran yang tepat dan sesuai agar tumbuh berbagai kegiatan belajar siswa sehubungan dengan peningkatan hasil belajar siswa tersebut.

Namun berdasarkan pengamatan secara terbatas, kemampuan mengajar dikalangan guru masih rendah. Hal ini dapat dilihat dari cara mengajar guru yang kurang kreatif dalam menentukan metode mengajar yang tepat untuk menyampaikan materi bahan ajar. Guru hanya memindahkan kemampuannya kepada siswa, dimana tugas guru adalah memberi dan tugas siswa adalah menerima. Pada umumnya transformasi pengetahuan kepada siswa melalui penuturan lisan atau ceramah. Dalam hal ini guru yang efektif dan siswa cenderung pasif. Akibatnya pembelajaran menjadi tidak efektif dan tujuan pembelajaran yang diharapkan tidak tercapai.

Guru yang efektif harus memiliki tiga kemampuan dasar yaitu (1) memiliki kemampuan yang luas dalam bidang ilmu yang diajarkan, (2) menguasai proses perencanaan dan pengelolaan pengajaran dan pembelajaran, (3) memiliki kemampuan memantau, menilai dan bertanggung jawab terhadap pelaksanaan tugas dan fungsinya sebagai guru. Tiga kemampuan dasar tersebut tentunya menjadi syarat minimal yang harus dimiliki guru agar proses pembelajaran berjalan menjadi efektif (Sidi, 2002:2). Hal ini juga tentu berlaku untuk guru IPA termasuk guru Biologi. Namun berdasarkan pengamatan secara terbatas, Guru Biologi belum memiliki tiga kemampuan dasar tersebut sehingga hal ini berdampak pada proses pembelajaran di kelas dan pada akhirnya berpengaruh pada hasil belajar siswa.

Hasil penelitian yang dilakukan TIMSS

(Trend Of International Mathematic and Science Study) tahun 2007 menunjukan bahwa nilai rata-rata sains yang dicapai negara Indonesia adalah 427 atau berada pada peringkat 35 dari 49 negara. Selain itu, hasil penelitian yang dilakukan oleh IMSTEP-JICA dalam Marsigit ( 2009) juga menunjukan bahwa dalam pembelajaran matematika dan sains, guru terlalu berkonsentrasi pada hal-hal yang terlalu prosedural dan mekanistik, pembelajaran berpusat pada guru, konsep matematis disampaikam secara formatif, dan siswa dilatih menyelesaikan soal tanpa pemahaman yang mendalam. Berdasarkan survei awal peneliti pada SMP Negeri 2 Larantuka, hasil belajar Biologi pada sekolah tersebut hanya $30 \%$ siswa yang mencapai nilai di atas 75 , dan $70 \%$ siswa lainnya masih di bawah rata-rata.

Kegiatan pembelajaran Biologi pada SMP Negeri 2 Larantuka pada umumnya masih menggunakan metode belajar lama yaitu metode belajar konvensional (ceramah). Hal ini diketahui berdasarkan hasil wawancara terhadap beberapa guru khususnya guru Biologi di SMP Negeri 2 Larantuka. Siswa dan guru disekolah tersebut memprediksikan bahwa hasil belajar siswa yang belum optimal disebabkan oleh beberapa faktor, yakni (1) metode belajar konvensional yang masih dominan dalam pembelajaran, sehingga menimbulkan kejenuhan pada siswa, (2) siswa kurang dilibatkan dalam kegiatan pembelajaran, (3) karakteristik pelajaran Biologi yang bersifat abstrak sehingga menyebabkan siswa sulit memahami pelajaran tersebut, (4) guru belum memperhatikan karakteristik dari materi tersebut, dan karakteristik siswa (gaya belajar) yang merupakan salah satu faktor pendukung dalam proses pembelajaran, (5) pembelajaran secara konvensional atau ceramah, kurang memfasilitasi siswa untuk kerjasama tim antar satu siswa dengan siswa lainnya. Sehingga perlu adanya suatu metode pembelajaran yang dapat memberikan kemudahan siswa untuk mempelajari ilmu Biologi secara baik dan benar.

Berbagai metode tersebut dapat diterapkan secara terpisah maupun dipadukan/dikombinasikan diantara metode pembelajaran yang ada pada pelajaran Biologi. Metode yang bisa digunakan dalam pelajaran Biologi pada materi sistem pencernaan adalah metode diskusi dan metode demonstrasi. Metode diskusi adalah cara penyajian bahan pelajaran dimana guru memberikan kesempatan 
kepada siswa untuk perbincangan ilmiah guna mengumpulkan pendapat, membuat kesimpulan, atau menyusun berbagai alternatif pemecahan suatu masalah (Hasibuan dan Moedjono, 2006:20). Salah satu tujuan dari metode diskusi adalah mengembangkan keterampilan bertanya, berkomunikasi, menafsirkan dan menyimpulkan pada diri siswa. Sedangkan metode demonstrasi adalah suatu metode yang cara penyajian pelajaran dengan memperagakan atau mempertunjukan kepada siswa suatu proses, situasi atau benda tertentu yang sedang dipelajari baik dalam bentuk tiruan yang dipertunjukan oleh guru atau sumber belajar lainnya yang ahli dalam topik bahasan (Sumantri, 2001:82). Tujuan dari metode demonstrasi adalah peniruan terhadap model yang dapat dilakukan dan memberikan pengalaman belajar melalui penglihatan dan pendengaran.

Selain metode pembelajaran, guru perlu memahami karakteristik siswa yang dapat mempengaruhi hasil belajarnya. Karakteristik siswa yang dimaksud dalam konteks penelitian ini adalah gaya belajar. Gaya belajar merupakan faktor-faktor yang mempengaruhi hasil belajar siswa. Tiap siswa belajar menurut caranya sendiri atau yang biasa disebut dengan gaya belajar, guru juga memiliki gaya mengajar masing-masing (Nasution, 2010:93). Satu individu dengan individu yang lain akan memiliki cara belajar yang berbeda-beda, begitu pula dengan guru. Tetapi guru kurang dalam hal pemahaman kondisi siswa sehingga model yang dikembangkan cenderung tidak dapat meningkatkan peran serta siswa secara optimal (Aunurrahman, 2010:140). Gaya belajar merupakan pendekatan yang menjelaskan mengenai bagaimana individu belajar atau cara yang ditempuh oleh masingmasing orang untuk berproses dalam mengumpulkan informasi (Gufron, 2013:42). Gaya belajar memiliki banyak jenis, antara lain jenis visual yang menekankan pada penglihatan, auditorial yang lebih memfokuskan pada pendengaran dan kinestetik yang lebih menyukai belajar dengan cara melakukan atau mengalami secara langsung.

Gaya belajar seseorang adalah kombinasi dari bagaimana ia menyerap dan kemudian mengatur serta mengolah informasi". Menurut Nasution (2003:55), "gaya belajar atau Learning style adalah cara bereaksi dan menggunakan perangsang-perangsang yang diterimanya dalam proses belajar". Lebih lanjut dikatakan gaya belajar adalah cara yang konsisten yang dilakukan oleh siswa dalam menangkap stimulus atau informasi, cara mengingat, berpikir dan memecahkan persoalan. Guru perlu mengetahui tipe gaya atau gaya belajar siswanya, agar guru dapat menyesuaikan metode apa yang akan diterapkan pada saat mengajar sehingga tujuan pengajaran yang telah dirumuskan oleh guru dapat tercapai.

Masalah pokok yang akan diungkapkan dalam penelitian ini adalah seberapa tinggi pengaruh penggunaan metode diskusi, metode demonstrasi dan gaya belajar yang berbeda terhadap hasil belajar Biologi siswa kelas VIII SMP Negeri 2 larantuka.

Secara khusus rumusan masalah yang peneliti tetapkan adalah sebagai berikut:

1. Apakah penggunaan metode diskusi dan metode demonstrasi berpengaruh terhadap hasil belajar Biologi siswa kelas VIII SMP Negeri 2 Larantuka Kabupaten Flores Timur?

2. Apakah gaya belajar berpengaruh terhadap hasil belajar Biologi siswa kelas VIII SMP Negeri 2 Larantuka Kabupaten Flores Timur?

3. Apakah ada interaksi antara pengunaan metode diskusi dan demonstrasi dengan gaya belajar yang berbeda terhadap hasil belajar Biologi siswa kelas VIII SMP Negeri 2 Larantuka Kabupaten Flores Timur?

Penelitian ini bertujuan untuk membuktikan (1) ada pengaruh penggunaan metode diskusi dan demonstrasi terhadap hasil belajar Biologi siswa kelas VIII SMP Negeri 2 Larantuka Kabupaten Flores Timur; (2) ada 
pengaruh gaya belajar terhadap hasil belajar Biologi siswa kelas VIII SMP Negeri 2 Larantuka Kabupaten Flores Timur; dan (3) ada interaksi antara metode diskusi dan demonstrasi dengan gaya belajar terhadap hasil belajar Biologi siswa SMP Negeri 2 Larantuka Kabupaten Flores Timur. Hasil penelitian ini diharapkan bermanfaat untuk: (1) memberikan informasi praktis bagi guru tentang metode diskusi dan demonstrasi sebagai salah satu metode alternatif pembelajaran Biologi yang dikenal sulit bagi siswa, sehingga dengan menerapkan kedua metode tersebut dapat meningkatkan hasil belajar Biologi bagi siswa SMP di Larantuka; (2) sebagai salah satu kajian teoritik tentang pembelajaran Biologi dengan metode diskusi dan demonstrasi sebagai upaya meningkatkan hasil belajar Biologi siswa SMP di Larantuka; dan (3)Sebagai salah satu upaya mendukung dan memperkuat hasil penelitian tentang penggunaan metode diskusi dan demonstrasi pada pembelajaran Biologi dalam usaha untuk meningkatkan prestasi belajar Biologi siswa SMP yang ada di Larantuka.

\section{Metode Penelitian}

Penelitian ini menggunakan rancangan Quasi Experiment Control Group Pretest Postest, Non Equivalent Design; dengan melibatkan 62 siswa dari 193 siswa kelas VIII SMP Negeri 2 Larantuka sebagai subyek penelitian. Rancangan penelitian dapat dapat diuraikan sebagai berikut.

$\begin{array}{lll}\mathrm{O}_{1} & \mathrm{X}_{1} & \mathrm{O}_{2} \\ \mathrm{O}_{1} & \mathrm{X}_{2} & \mathrm{O}_{2}\end{array}$

Keterangan:

$\mathrm{X}_{1}$ : Perlakuan Penerapan dengan Metode Diskusi

$\mathrm{X}_{2}$ : Perlakuan Penerapan dengan Metode Demonstrasi

$\mathrm{O}_{1}$ : Pretest untuk Mengukur Hasil Belajar Sebelum Perlakuan

$\mathrm{O}_{2}$ : Posttest untuk Mengukur Hasil Belajar Setelah Perlakuan
Data-data penelitian dikumpulkan dengan menggunakan instumen angket untuk gaya belajar, dan instrument tes untuk hasil belajar. Data-data penelitian selanjutnya dianalisis dengan menggunakan teknik analisis Anava 2 x 2 dengan bantuan SPSS for windowns versi 14.0. sebelum data-data penelitian dianalisis, terlebih dahulu dilakukan uji normalitas dan uji homogenitas variansi.

Tabel 1. Rancangan Analisis Anava 2 x 2

\begin{tabular}{|l|l|l|}
\hline \multicolumn{1}{|c|}{ Metode } & \multicolumn{2}{|l|}{ Metode } \\
\cline { 2 - 3 } Gaya Belajar & $\begin{array}{l}\text { Metode } \\
\text { Diskusi }\end{array}$ & $\begin{array}{l}\text { Metode } \\
\text { Demonstrasi }\end{array}$ \\
\hline Auditorial & 19 & 18 \\
\hline Visual & 12 & 13 \\
\hline Jumlah & 31 & 31 \\
\hline Jumlah total & 62 & \\
\hline
\end{tabular}

Keterangan:

y1A : Kelas Metode Diskusi dengan Gaya Belajar Auditorial

y2A : Kelas Metode Demonstrasi dengan Gaya Belajar Auditorial

y1V : Kelas Diskusi dengan Gaya Belajar Visual

y2V : Kelas Metode Demonstrasi dengan Gaya Belajar Visual

\section{HASIL PENELITIAN}

Hasil penelitian akan disajikan deskripsi data hasil penelitian, uji persyaratan analisis dan pengujian hipotesis.

A. Deskripsi Hasil Belajar

1. Data Hasil Belajar Biologi Pada Kelas Metode Diskusi dan Kelas Metode Demonstrasi.

Data hasil belajar siswa sebelum dan sesudah menggunakan metode belajar diskusi dan demonstrasi diuraikan pada tabel 2 sebagai berikut. 
Tabel 2. Data hasil belajar Biologi ditinjau dari Metode belajar

\begin{tabular}{|l|l|l|l|l|}
\hline Hasil Statisitik & \multicolumn{3}{l|}{ Metode } & \multicolumn{2}{l|}{} \\
\hline & Diskusi & \multicolumn{2}{l|}{ Demonstrasi } \\
\hline & Pre test & Postest & Pre test & Posttest \\
\hline Mean & 31 & 31 & 31 & 31 \\
\hline Std. Deviation & 52,04 & 76,770 & 65,5935 & 81,5065 \\
\hline Std. Error of Mean & 1,3497 & 8,224 & 15,201 & 8,209 \\
\hline Minimum & 2,42411 & 1,477 & 2.73022 & 1,4731 \\
\hline Maximum & 26,7 & 66,7 & 40 & 66,7 \\
\hline Median & 86,7 & 93,3 & 93,3 & 9,3 \\
\hline & 53,3 & 73,3 & 66,7 & 80 \\
\hline & & & & \\
\hline
\end{tabular}

Pada tabel di atas dapat diketahui bahwa, nilai rata-rata pre test kelas diskusi yaitu 52,04 dan nilai rata-rata postetsnya 76,770. Sedangkan pada kelas demonstrasi, nilai ratarata pre testnya 65,5935 dan nilai rata-rata pos testnya 81,5065 .

2. Data hasil Belajar Siswa ditinjau dari Gaya Belajar

Data gaya belajar siswa berdasarkan perhitungan jumlah jawaban, gaya belajar siswa pada kelas dengan metode diskusi dan kelas dengan metode demonstrasi didominasi oleh siswa dengan gaya belajar auditori. Jumlah siswa yang memiliki gaya belajar auditori pada kelas diskusi sebanyak 61,3\% atau 19 siswa dan siswa yang memiliki gaya belajar visual sebanyak 38,7\% atau 12 siswa. Sedangkan pada kelas demonstrasi, jumlah siswa yang memiliki gaya belajar auditori sebayak 58,1\% atau 18 siswa, dan siswa yang memiliki gaya belajar visual sebanyak 41,9\% atau 13 siswa. Untuk lebih lengkapnya data persebaran gaya belajar siswa pada kelas dengan metode diskusi dan kelas dengan metode demostrasi secara singkat disajikan dalam tabel berikut.

Tabel 3. Sebaran Gaya Belajar Siswa Pada Kelas dengan Metode Diskusi

\begin{tabular}{|l|l|l|l|}
\hline No & Gaya Belajar & Frekuensi & Persentase \\
\hline 1 & Visual & 12 & 61,3 \\
\hline 2 & Auditori & 19 & 38,7 \\
\hline & Total & 31 & 100 \\
\hline
\end{tabular}

Tabel 4. Sebaran Gaya Belajar Siswa Pada Kelas dengan Metode Demonstrasi

\begin{tabular}{|l|l|l|l|}
\hline No & $\begin{array}{l}\text { Gaya } \\
\text { Belajar }\end{array}$ & Frekuensi & Persentase \\
\hline 1 & Visual & 13 & 58,1 \\
\hline 2 & Auditori & 18 & 41,9 \\
\hline & Total & 31 & 100 \\
\hline
\end{tabular}

Data hasil belajar siswa ditinjau dari gaya belajar pada kelas diskusi dan demonstrasi sebelum dan sesudah diberi perlakuan diuraikan pada tabel 5 dan 6 sebagai berikut.

Tabel 5. Data Hasil Belajar Biologi ditinjau dari Gaya Belajar Siswa Pada Kelas dengan Metode Diskusi

\begin{tabular}{|c|c|c|c|c|}
\hline Hasil Statisitik & \multicolumn{4}{|c|}{ Gaya Belajar } \\
\hline & \multicolumn{2}{|l|}{ Auditori } & \multicolumn{2}{|l|}{ Visual } \\
\hline & Pre test & Posttest & Pre test & Posttest \\
\hline $\mathrm{N}$ & 19 & 19 & 12 & 12 \\
\hline Mean & 56,4947 & 76,8368 & 44.9833 & 74.4417 \\
\hline Std. Deviation & 14,29734 & 8,41706 & 8.58591 & 6.24696 \\
\hline $\begin{array}{lll}\text { Std. Error of } \\
\text { Mean }\end{array}$ & 23,2800 & 1,93101 & 2.47854 & 1.80334 \\
\hline Minimum & 26.7 & 93.3 & 33.30 & 66.70 \\
\hline Maximum & 86.7 & 66.7 & 53.30 & 86.70 \\
\hline
\end{tabular}

Pada tabel 5. di atas, diketahui bahwa jumlah sampel yang diajar dengan menggunakan metode diskusi ada 31 siswa. Jumlah sampel yang memiliki gaya belajar auditori sebanyak 19 siswa. Hasil Pre test dengan gaya belajar auditori yaitu, nilai ratarata yang diperoleh adalah 54,494; dan nilai rata-rata post tes, 76,836. Sedangkan Jumlah sampel yang memiliki gaya belajar visual ada 12 siswa. Hasil Pre test dengan gaya belajar auditori yaitu, nilai rata-rata yang diperoleh adalah 44,983 dan, nilai rata-rata hasil post tes yang diperoleh adalah 74,441.

Tabel 6. Data Hasil Belajar Biologi ditinjau dari Gaya Belajar Siswa Pada Kelas dengan Metode Demonstrasi

\begin{tabular}{|l|l|l|l|l|}
\hline \multirow{2}{*}{ Hasil Statistik } & \multicolumn{4}{l|}{ Gaya Belajar } \\
\cline { 2 - 5 } & \multicolumn{2}{|l|}{ Auditori } & \multicolumn{2}{l|}{ Visual } \\
\cline { 2 - 5 } & Pre test & Posttest & Pre test & Posttest \\
\hline \multirow{2}{*}{$\mathrm{N}$} & 18 & 18 & 13 & 13 \\
\hline Mean & 65.56 & 80.75 & 65.65 & 82.5538 \\
\hline Std. Deviasi & 13.757 & 8.8225 & 17.5947 & 7.474 \\
\hline Std. Error of Mean & 3.2425 & 2.0794 & 4.87991 & 2.0729 \\
\hline Maximum & 80 & 93.3 & 93.3 & 93.3 \\
\hline Minimum & 40 & 66.7 & 40 & 66.7 \\
\hline
\end{tabular}

Pada tabel 5 di atas diketahui bahwa
jumlah sampel yang diajar dengan 
menggunakan metode diskusi ada 31 siswa. Jumlah siswa yang memiliki gaya belajar Auditori ada 18 siswa. Nilai rata-rata pre test dengan gaya belajar auditori yaitu, nilai ratarata yang diperoleh adalah 65,56 , dan nilai ratarata post tesnya, adalah 80,75 ; nilai tertinggi 93,3.Sedangkan jumlah siswa yang memiliki gaya belajar visual sebanyak 13 orang dengan nilai rata-rata hasil pre test yaitu 65,65 ; nilai tertinggi 93,3 dan nilai rata-rata hasil post tesnya adalah 82,553; nilai tertinggi 93,3.

\section{B. Uji Persyaratab Analisis Data}

1. Uji Normalitas

Hasil uji normalitas sebaran data hasil belajar siswa pada Pre test dengan menggunakan One Sample Kolmogorov-Sminov Test, diperoleh nilai statistik $=2,672$ dengan nilai signifikan $=0,382$ (tidak signifikan) yang berarti data tersebut berdistribusi normal. Hasil uji normalitas sebaran data hasil belajar Post test siswa pada kelas yang menggunakan metode diskusi dengan menggunakan One Sample Kolmogorov-Sminov Test, diperoleh nilai statistik $=1,180$ dan nilai signifikan $=$ 0,124 ( tidak siginifikan) yang berarti data tersebut berdistribusi normal. Hasil uji normalitas data hasil belajar Post test siswa pada kelas dengan menggunakan metode demonstrasi dengan menggunakan One Sample Kolmogorov-Sminov Test, diperoleh nilai statistik $=1,049$ dan nilai signifikan 0,222 (tidak signifikan) yang berarti sebaran data tesebut berdistribusi normal. Berdasarkan hasil perhitungan dapat diketahui hasil seperti yang terlihat pada tabel berikut.

Tabel 4.12. Hasil Uji Kenormalan Data

\begin{tabular}{|l|l|l|l|}
\hline Data & $\begin{array}{l}\text { Kolmogorov- } \\
\text { Smirnov Z }\end{array}$ & $\begin{array}{l}\text { Asymp. Sig. } \\
\text { (2-tailed) }\end{array}$ & Keterangan \\
\hline Nilai Pre test & 0,908 & 0,382 & Normal \\
\hline Nilai Posttes Kelas Diskusi & 1,18 & 0,124 & Normal \\
\hline Nilai Posttes Kelas Demontrasi & 1,049 & 0,222 & Normal \\
\hline
\end{tabular}

2. Uji Homogenitas

Hasil uji homogenitas variansi data hasil belajar siswa pada kelompok dengan metode diskusi dan kelompok dengan metode demonstrasi, diperoleh nilai levene statistik $=$
0,001 , df $1=1$ dan $\mathrm{df} 2=60$ pada taraf signifikan 0,977 yang berarti data tersebut variasinya heterogen (karena taraf signifikannya pada batas atas, data ini diasumsikan variasinya homogen). Hasil uji homogenitas variansi data hasil belajar dan gaya belajar siswa, diperoleh nilai levene statistik $=0,969, \mathrm{df} 1=1, \mathrm{df} 2=60$ pada taraf signifikan $=0,329$ (tidak signifikan) yang berarti data tersebut variasinya homogen. Data hasil uji Levene's Test of homogeneity of variance seperti tercantum dalam tabel berikut ini.

Tabel 4.13. Hasil Uji Homogenitas Data

\begin{tabular}{|l|l|l|l|l|l|}
\hline Data & $\begin{array}{l}\text { Levene } \\
\text { Statistic }\end{array}$ & df1 & df2 & Sig & Keterangan \\
\hline & & & & & \\
\hline Nilai Postets*Metode & 0,001 & 1 & 60 & 0,977 & Normal \\
\hline $\begin{array}{l}\text { Nilai Posttest*Gaya } \\
\text { Belajar }\end{array}$ & 0,969 & 1 & 60 & 0,329 & Normal \\
\hline
\end{tabular}

C. Uji Hipotesis Anava 2 x 2

Uji hipotesis pada penelitian ini menggunakan analisis varian dua jalur untuk sel yang tidak sama melalui Uji Univariate of Variance. Persyaratan uji anava dua jalur yaitu uji normalitas dan uji homogenitas telah terpenuhi yakni sampel berdistribusi normal dan memiliki variasi yang sama. kriteria yang digunakan untuk mengambil keputusan hipotesis adalah tingkat signifikasi $(\alpha)$ : 0,05 atau 5\% dengan daerah kritisnya yaitu $\mathrm{H}_{0}$ ditolak jika signifikasi probabilitas $(P$-Value $)<$ $\alpha(0,05)$. Hal ini berarti jika signifikasi probabilitas $(P$-Value $)<\alpha(0,05)$ maka hipotesis nihil $\left(\mathrm{H}_{0}\right)$ ditolak, dan sebaliknya jika signifikasi probabilitas $(P$-Value $)>\alpha(0,05)$. Pengujian hipotesis dilakukan untuk mengetahui apakah hipotesis yang dirumuskan dapat teruji kebenarannya atau tidak terbukti. Maka untuk pengujian hipotesis dalam penelitian ini menggunakan teknik ANAVA dua jalan. Untuk pengujian hasil analisis data yang diperoleh dari hasil perhitungan dengan menggunakan uji Analisis Variansi dua jalan, maka hipotesis yang telah dirumuskan dapat terjawab dalam tabel sebagai berikut.

Tabel 4.13 Hasil Uji Analisis Data: Univariate Analysis of Variance 


\begin{tabular}{|l|l|l|l|l|l|}
\hline Source & $\begin{array}{l}\text { Type III Sum } \\
\text { of Squares }\end{array}$ & Df & Mean Square & F & Sig. \\
\hline Corrected Model & $478.374(\mathrm{a})$ & 3 & 159.458 & 2.361 & .081 \\
\hline Intercept & 371952.229 & 1 & 371952.229 & 5508.191 & .000 \\
\hline $\begin{array}{l}\text { Gaya Belajar } \\
\text { Metode }\end{array}$ & 14.850 & 1 & 14.850 & .220 & .641 \\
\hline $\begin{array}{l}\text { Gaya Belajar } \\
\text { Metode }\end{array}$ & 420.148 & 1 & 420.148 & 6.222 & .015 \\
\hline $\begin{array}{l}\text { Error } \\
\text { Total }\end{array}$ & 117.000 & 1 & 117.000 & 1.733 & .193 \\
\hline Corrected Total & 3916.573 & 58 & 67.527 & & \\
\hline
\end{tabular}

1. Uji Hipotesis Pertama

Untuk uji hipotesis pertama yaitu ada pengaruh penggunaan metode diskusi dan demonstrasi terhadap hasil belajar Biologi siswa SMP Negeri 2 Larantuka Kabupaten Flores Timur, digunakan kaidah bahwa hipotesis alternatif $\left(\mathrm{H}_{1}\right)$ diterima bila peluang kesalahan $(\mathrm{p}) \leq 0,05$ atau pada taraf signifikansi di bawah $95 \%$, dan hipotesis nihil $\left(\mathrm{H}_{0}\right)$ diterima bila peluang kesalahan (p) >0,05 atau taraf signifikan di bawah 95\%. Ternyata, berdasarkan hasil uji Univariate of Variance statistik parametrik diperoleh nilai Sum of Squares $=420,148$, derajat kebebasan $(\mathrm{df})=1$, nilai $\mathrm{F}=0,015$ pada taraf signifikan $=0,015$ yang berarti signifikan. Berdasarkan bukti analisis tersebut, hipotesis $\mathrm{H}_{1}$ ada pengaruh penggunaan metode diskusi dan demonstrasi terhadap hasil belajar Biologi siswa SMP Negeri 2 Larantuka Kabupaten Flores Timur diterima. Ringkasan hasil analisis uji Univariate of Variance diuraikan pada tabel 4.14. sebagai berikut.

Tabel 4.14. Hasil Analisis Pengaruh Metode Diskusi dan Demonstrasi Terhadap Hasil Belajar Biologi

\begin{tabular}{|l|l|l|l|l|} 
Metode & Jumlah Kuadrat & $\begin{array}{l}\text { Derajat } \\
\text { Kebebasan }\end{array}$ & F & $\begin{array}{l}\text { Taraf } \\
\text { Signifikan }\end{array}$ \\
\hline & (Sum of Squares) & (df) & & (2 ekor) \\
\hline \multirow{2}{*}{ Diskusi } & & & & \\
\cline { 2 - 5 } & 420,148 & 1 & 0,015 & 6,222 \\
\hline Demonstrasi & & & & \\
\hline
\end{tabular}

2. Hipotesis Kedua

Untuk menguji hipotesis kedua yaitu ada pengaruh gaya belajar yang berbeda terhadap hasil belajar Biologi SMP Negeri 2 Larantuka Kabupaten Flores Timur, digunakan kaidah bahwa hipotesis alternatif $\left(\mathrm{H}_{1}\right)$ diterima bila peluang kesalahan $(\mathrm{p}) \leq 0,05$ atau pada taraf signifikansi di bawah 95\%, dan hipotesis nihil
$\left(\mathrm{H}_{0}\right)$ diterima bila peluang kesalahan $(\mathrm{p})>0,05$ atau taraf signifikan di bawah $95 \%$. Berdasarkan hasil uji analisis nilai Sum of Squares $=14,850$, derajat kebebasan $(\mathrm{df})=1$, nilai $F=0,220$ pada taraf signifikan $=0,641$ yang berarti tidak signifikan. Berdasarkan bukti analisis tersebut, hipotesis alternatif $\left(\mathrm{H}_{1}\right)$ ada pengaruh gaya belajar yang berbeda terhadap hasil belajar Biologi siswa SMP Negeri 2 Larantuka Kabupaten Flores Timur ditolak. Ringkasan hasil analisis uji Anawa Two Way tersebut, diuraikan pada tabel 4.15. sebagai berikut.

Tabel 4.15. Hasil Analisis Pengaruh Gaya Belajar yang Berbeda Terhadap Hasil Belajar Biologi

\begin{tabular}{|l|l|l|l|l|}
\hline $\begin{array}{l}\text { Gaya } \\
\text { Belajar }\end{array}$ & Jumlah Kuadrat & $\begin{array}{l}\text { Derajat } \\
\text { Kebebasan }\end{array}$ & F & Taraf Signifikan \\
\hline & (Sum of Squares) & (df) & & (2 ekor) \\
\hline \multirow{2}{*}{ Auditori } & & & & \\
\cline { 2 - 5 } & 14,850 & 1 & 0,220 & 0,641 \\
\hline Visual & & & & \\
\hline
\end{tabular}

3. Hipotesis Ketiga

Untuk menguji hipotesis ketiga yaitu ada pengaruh interaksi antara penggunaan metode dengan gaya belajar yang berbeda terhadap hasil belajar Biologi siswa kelas VIII SMP Negeri 2 Larantuka Kabupaten Flores Timur, digunakan kaidah bahwa hipotesis alternatif $\left(\mathrm{H}_{1}\right)$ diterima bila peluang kesalahan (p) $\leq 0,05$ atau pada taraf signifikansi di bawah $95 \%$, dan hipotesis nihil $\left(\mathrm{H}_{0}\right)$ diterima bila peluang kesalahan $(\mathrm{p})>0,05$ atau taraf signifikan di bawah 95\%. Berdasarkan hasil uji analisis Univariate of variance nilai Sum of Squares $=117,000$ derajat kebebasan $(\mathrm{df})=1$, nilai $F=1,733$ pada taraf signifikan $=0,193$ yang berarti tidak signifikan. Berdasarkan bukti analisis tersebut, hipotesis alternatif $\left(\mathrm{H}_{1}\right)$ ada pengaruh interaksi antara metode dengan gaya belajar yang berbeda terhadap hasil belajar Biologi siswa SMP Negeri 2 Larantuka Kabupaten Flores Timur ditolak. Ringkasan hasil analisis uji Univariate of variance tersebut diuraikan pada tabel 4.16. sebagai berikut. 
Tabel 4.16. Hasil Analisis Pengaruh Interaksi antara Metode dengan Gaya Belajar yang Berbeda terhadap Hasil Belajar Biologi

\begin{tabular}{|l|l|l|l|l|} 
& Jumlah Kuadrat & $\begin{array}{l}\text { Derajat } \\
\text { Kebebasan }\end{array}$ & F & $\begin{array}{l}\text { Taraf } \\
\text { Signifikan }\end{array}$ \\
\hline \multirow{2}{*}{ Metode } & & & & \\
\cline { 2 - 5 } & 117,000 & 1 & 1,733 & 0,193 \\
\cline { 3 - 5 } Gaya Belajar & & & & \\
\cline { 2 - 5 } & & & & \\
\hline
\end{tabular}

\section{KESIMPULAN}

Simpulan yang didapat dari penelitian yang telah dilakukan adalah sebagai berikut:

1. Terdapat pengaruh yang signifikan penggunaan metode diskusi dan metode demonstrasi terhadap hasil belajar Biologi siswa kelas VIII SMP Negeri 2 Larantuka Kabupaten Flores Timur.

2. Tidak terdapat pengaruh gaya belajar terhadap hasil belajar Biologi siswa kelas VIII SMP Negeri 2 Larantuka Kabupaten Flores Timur.

3. Tidak terdapat interaksi antara metode diskusi dan demonstrasi dengan gaya belajar terhadap hasil belajar Biologi siswa kelas VIII SMP Negeri 2 Larantuka Kabupaten Flores Timur.

\section{DAFTAR PUSTAKA}

Aunurrahman. 2010. Belajar dan Pembelajaran. Bandung: Alfabeta.

Gufron, M. N. Dan Risnawati, R.S. 2013. Gaya Belajar Kajian Teoritik. Yogjakarta: Pustaka Pelajar.

Hamdani. (2011). Strategi Belajar Mengajar. Bandung: CV Pustaka Setia

Hasibuan, JJ dan Moedjiono. 2008. Proses Belajar Mengajar. Bandung: PT Remaja Rosda Karya Jakarta: Bumi Aksara

Marsigit. 2009. Matematika SMP Kelas VIII. Yudhistira. Jakarta

Muldayanti, N. D. 2013. Pembelajaran Biologi Model STAD dan TGT Ditinjau Dari Keingintahuan dan Minat Belajar Siswa. Jurnal Pendidikan IPA Indonesia, 2(1), 12-17
Nasution S. 2010. Berbagai Pendekatan dalam Proses Belajar dan Mengajar.

Nasution, S. 2003. Berbagai Pendekatan dalam Proses Belajar Mengajar. Jakarta: Bumi Aksara

Sidi, I. J. 2002. Rambu-rambu Penilaian Kinerja Sekolah. Jakarta: Depdiknas. 